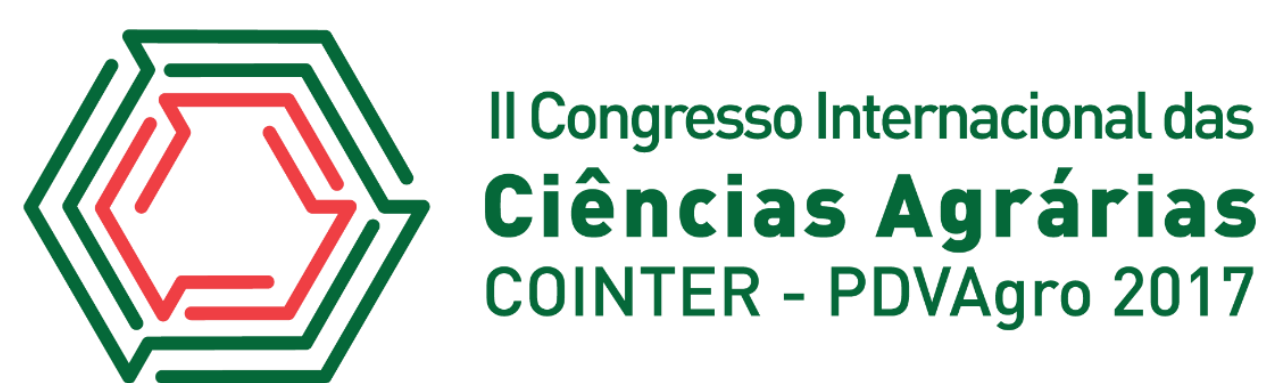

\title{
USO DE UMECTANTES SOBRE AS CARACTERÍSTICAS FÍSICAS DE QUALIDADE DA CARNE OVINA
}

Apresentação: Pôster

Ana Paula Pinheiro de Assis ${ }^{1}$; Andreza Kelly Santos de Andrade ${ }^{2}$; Vitor Lucas de Lima Melo ${ }^{3}$; Lucas de Oliveira Soares Rebouças ${ }^{4}$; Patrícia de Oliveira Lima ${ }^{5}$

\section{Introdução}

O desenvolvimento de novos produtos mais competitivos e com valor agregado tem se mostrado como fator decisivo na participação de empresas menores no mercado. A fim de atender à demanda dos consumidores, em associação ao crescimento da população urbana brasileira, mudanças significativas têm ocorrido nos padrões de consumo alimentar, entre elas, a redução do consumo de alimentos que demandam mais tempo para preparo e o aumento do consumo de alimentos preparados (SCHLINDWEIN \& KASSOUF, 2006).

Inicialmente utilizada como prática culinária, a marinação se estendeu ao nível industrial, tendo sido utilizada há décadas pela indústria de carne de frango. Mais recentemente, tem se estendido à carne suína e, em menores proporções, à carne bovina, sendo obtidos avanços tecnológicos e fazendo com que a comercialização de carne in natura venha cedendo lugar às carnes semipreparadas, adicionadas de soluções (XIONG, 2005; SCHIRMER et al., 2009)

\section{Fundamentação Teórica}

As técnicas de injeção e marinação quando aplicadas, ao mesmo tempo em que devem utilizar ingredientes em concentrações suficientes para incrementar atributos sensoriais, não podem gerar efeitos adversos no sabor e na coloração, nem causar maciez excessiva, fatores que podem causar rechaço dos consumidores, e também não devem objetivar a melhora da matéria-prima de má qualidade, sob risco de não surtir os efeitos esperados (SHEARD \& TALI, 2004; BAUBLITS et al.,

\footnotetext{
${ }^{1}$ Pós-graduanda na Universidade Federal Rural do Semiárido, UFERSA, pinheiropaula87@hotmail.com

${ }^{2}$ Graduada em Zootecnia na Universidade Federal Rural do Semiárido, UFERSA, andrezak.andrade@gail.com

${ }^{3}$ Graduando em Zootecnia na Universidade Federal Rural do Semiárido, UFERSA, vitor IIm@hotmail.com

4 Pós-graduando na Universidade Federal Rural do Semiárido, UFERSA; lucaslosr@gmail.com

${ }^{5}$ Docente na Universidade Federal Rural do Semiárido, UFERSA, pattlima@ufersa.edu.br
} 
2006). Embora os produtos marinados tenham um mercado potencialmente crescente, a quantificação de sua aceitabilidade em relação à carne in natura ainda é necessária, sendo os consumidores esclarecidos quanto à natureza e às vantagens da carne injetada (BAUBLITS et al., 2006).

Estudos sobre uso de diferentes concentrações de aditivos na carne ovina marinada, seja isolado ou conjuntamente, ainda são escassos, fazendo-se necessárias pesquisas mais aprofundadas sobre os seus efeitos. Assim, o objetivo com este trabalho foi avaliar o efeito do lactato de sódio, tripolifosfato de sódio e a da associação destes na qualidade da carne ovina.

\section{Metodologia}

A carne ovina utilizada foi oriunda de 24 animais sem padrão racial definido (SPRD) criados em sistema intensivo no município de Governador Dix-Sept Rosado/RN. A idade média de abate dos animais foi de 6 meses e o abate foi conduzido no Abatedouro Frigorífico Industrial de Mossoró/RN (AFIM). Após o abate, as carcaças foram armazenadas em câmara frigorifica, sob temperatura de 4 a $7^{\circ} \mathrm{C}$ durante o período de 24 horas. Em seguida, foram realizados os cortes e foi selecionado para a análise o músculo Longíssimos dorsi (contra-filé), que permaneceu sob refrigeração até o preparo das amostras em laboratório. As amostras foram subdividida em quatro lotes, sendo cada um submetido a um tratamento, onde três destes utilizaram da adição de lactato de sódio (LS) e tripolifosfato de sódio (TPF), além do controle. As amostras foram imersas por 15 minutos em soluções com as concentrações: F0: carne controle; F1: carne adicionada de 5\% de lactato de sódio; F2: carne adicionada de 5\% de tripolifosfato de sódio e F3: carne adicionada de 5\% de lactato de sódio $+2,5 \%$ de tripolifosfato de sódio. Todas as amostras foram armazenadas em temperatura de refrigeração, $4^{\circ} \mathrm{C} \pm 1^{\circ}$, e posteriormente submetidas a análise.

As análises físicas foram realizadas no Laboratório de Análises Instrumentais e Sensoriais (LANIS) da UFERSA, e realizadas em duplicata, nos tempos de armazenamento 0, 3, 6, 9 e 12 dias de armazenamento refrigerado a $4^{\circ} \mathrm{C} \pm 1^{\circ}$. Para determinar a capacidade de retenção de água (CRA) foi realizada a medição de perda de água liberada quando aplicada uma pressão sobre o tecido muscular: $0,5 \mathrm{~g}$ de carne colocada em papéis-filtro e estes entre duas placas de acrílico, onde foram submetidos a um peso de $5 \mathrm{~kg}$ por 5 minutos (HAMM, 1960). Para a análise de perda de peso por cocção (PPC), foi realizada uma pesagem de duas porções da carne $(3,0 \times 3,0 \times 2 \mathrm{~cm})$, peso aproximadamente $25 \mathrm{~g}$, em seguida foram envolvidas em papel alumínio. A cocção das amostras foi 
realizada através da utilização de um grill durante 8 minutos, esfriadas em temperatura ambiente e pesadas novamente (OSÓRIO; OSÓRIO 1998). A força de cisalhamento foi mensurada com o auxilio de um texturômetro (TEXTURE ANALYZER TAXT-125), acoplado ao dispositivo Warner-Bratzler (HDP/WBV), foram retiradas 2 amostras por porção, no sentido das fibras, no formato de paralelepípedos com 1,5 x 3,0 x 1,5 cm. As amostras usadas para a FC foram as mesmas utilizadas na PPC (HAMM, 1960).

Para a análise estatística, os dados foram submetidos à análise de variância e teste de comparação de médias. Os efeitos dos diferentes tratamentos sobre cada variável foram comparados por meio do teste de Tukey, ao nível de 5\% de probabilidade, utilizando o SISVAR versão 5.6.

\section{Resultados e Discussões}

Com relação à capacidade de retenção de água (CRA), não houve padrão de variação entre os tratamentos P>0,05 (Tabela 1). No que diz respeito aos dias de armazenamento, observou-se que o LS provocou o incremento na CRA ao longo do período experimental, o que pode ser explicado pelo aumento do $\mathrm{pH}$ no período final de analise nas amostras de carne ovina marinada com o LS. Resultados divergentes foram obtidos por Vlahova-Vangelova et al. (2017), testando diferentes tipos de soluções para marinação em carne ovina, observaram que amostras marinadas com soluções de $2 \%$ de lactado de sódio tiveram menor CRA após o período de $48 \mathrm{~h}$.

No que diz respeito à perda de peso por cocção (PPC) Tabela 1, não houve diferença estatística entre os tratamentos e entre os dias de armazenamento ( $\mathrm{P}>0,05)$, sendo observados valores de PPC entre 33,39\% a 44,34\%. Valores acima dos observados por Zeola et al. (2005) testando o efeito de cloreto de cálcio injetado em carne ovina (PPC média de 28,54\%). Segundo Malheiros (2014), a proporção de água é maior em animais jovens e diminui em músculos com maiores índices de marmorização e com maior teor de gordura, isto pode explicar as altas perdas observadas nesse estudo, além da pouca influência dos aditivos neste parâmetro.

Quanto à força de cisalhamento (FC) verificou-se diferença estatística entre todos os tratamentos até o $3^{\circ}$ dia do período experimental, sendo que as amostras que foram imersas em aditivos obtiveram as menores médias de FC em relação ao controle. Entre os aditivos, os que apresentaram menores valores nos dias 0 e 3 de FC foram LS $\left(2,20\right.$ e 1,82 kgf/ $\left.\mathrm{cm}^{2}\right)$ e TPF $(2,83$ e $3,24 \mathrm{kgf} / \mathrm{cm}^{2}$ ), respectivamente. No dia 6 , os tratamentos controle e LSTPF obtiveram médias mais 
baixas que os aditivos utilizados isoladamente. Entre os aditivos, os que apresentaram menores valores nos dias 0 e 3 de FC foram LS (2,20 e 1,82 kgf/ $\left.\mathrm{cm}^{2}\right)$ e TPF $\left(2,83\right.$ e 3,24 kgf/ $\left.\mathrm{cm}^{2}\right)$, respectivamente. No dia 6, os tratamentos controle e LSTPF obtiveram médias mais baixas que os aditivos utilizados isoladamente. Observou-se que nos dias 9 e 12 todos os valores para FC dos tratamentos tenderam a diminuir em relação aos dias anteriores.

Tabela 1. Efeito de umectantes sobre a capacidade de retenção de água, perda de peso na cocção e força de cisalhamento na carne ovina. Fonte: própria

\begin{tabular}{|c|c|c|c|c|c|c|}
\hline \multirow{2}{*}{$\begin{array}{l}\text { Dias de } \\
\text { armazenamento }\end{array}$} & \multirow[b]{2}{*}{ Variável } & \multirow[b]{2}{*}{ Controle } & \multicolumn{3}{|c|}{ ADITIVOS } & \multirow[b]{2}{*}{$\mathrm{CV}(\%)$} \\
\hline & & & $\mathrm{LS}$ & TPF & LSTPF & \\
\hline 0 & \multirow{5}{*}{ CRA $(\%)$} & $61,83 \mathrm{ABa}$ & $56,83 \mathrm{Bc}$ & $61,71 \mathrm{ABa}$ & $66,28 \mathrm{Aa}$ & \multirow{6}{*}{5,02} \\
\hline 3 & & $58,51 \mathrm{Aa}$ & $59,05 \mathrm{Abc}$ & $60,02 \mathrm{Aa}$ & $57,61 \mathrm{Aab}$ & \\
\hline 6 & & $56,18 \mathrm{Aa}$ & $59,05 \mathrm{Abc}$ & $59,58 \mathrm{Aa}$ & $60,74 \mathrm{Aa}$ & \\
\hline 9 & & $61,71 \mathrm{Aa}$ & $67,18 \mathrm{Aab}$ & $62,79 \mathrm{Aa}$ & $63,87 \mathrm{Aa}$ & \\
\hline 12 & & $59,88 \mathrm{ABa}$ & $68,17 \mathrm{Aa}$ & $58,35 \mathrm{Ba}$ & $51,43 \mathrm{Bb}$ & \\
\hline $\mathbf{0}$ & \multirow{4}{*}{$\mathrm{PPC}(\%)$} & $37,71 \mathrm{Aab}$ & $36,58 \mathrm{Aa}$ & $37,38 \mathrm{Aa}$ & $33,39 \mathrm{Ab}$ & \\
\hline & & $43,77 \mathrm{Aa}$ & $36,34 \mathrm{Ba}$ & $36,49 \mathrm{Ba}$ & $38,82 \mathrm{ABab}$ & \multirow{4}{*}{5,97} \\
\hline 6 & & $40,06 \mathrm{Aab}$ & $36,92 \mathrm{Aa}$ & $40,67 \mathrm{Aa}$ & $40,81 \mathrm{Aa}$ & \\
\hline & & $36,09 \mathrm{Ab}$ & $35,47 \mathrm{Aa}$ & $41,19 \mathrm{Aa}$ & $39,88 \mathrm{Aab}$ & \\
\hline 12 & \multirow{6}{*}{ FC (Kgf) } & 43,08 $\mathrm{Aa}$ & $40,51 \mathrm{Aa}$ & $40,25 \mathrm{Aa}$ & 44,34 Aa & \\
\hline 0 & & $5,63 \mathrm{Aa}$ & $2,20 \mathrm{Dbc}$ & $2,83 \mathrm{Ca}$ & $5,18 \mathrm{Ba}$ & \multirow{5}{*}{7,1} \\
\hline & & 5,39 Aa & $1,82 \mathrm{Dc}$ & $3,24 \mathrm{Ca}$ & $4,05 \mathrm{Bb}$ & \\
\hline 3 & & 2,42 Bb & $3,19 \mathrm{Aa}$ & 3,13 Aa & $2,29 \mathrm{Bc}$ & \\
\hline $\mathbf{0}$ & & $1,32 \mathrm{Cc}$ & $2,38 \mathrm{Bb}$ & $1,45 \mathrm{Cb}$ & $3,72 \mathrm{Ab}$ & \\
\hline 12 & & $2,03 \mathrm{Ab}$ & $2,07 \mathrm{Abc}$ & $1,83 \mathrm{Ab}$ & $1,74 \mathrm{Ad}$ & \\
\hline
\end{tabular}

A,B Letras maiúsculas distintas na linha indicam diferença entre os tratamentos pelo teste Tukey $5 \%$.

a, b, c Letras minúsculas distintas na coluna indicam diferença entre os tempos de armazenamento pelo teste Tukey 5\%

\section{Conclusões}

A combinação do lactato de sódio e o tripolifosfato de sódio aumentam a maciez da carne ovina. 


\section{Referências}

BAUBLITS, R.T. et al. Pump rate and cooked temperature effects on pork loins instrumental, sensory descriptive and consumer-rated characteristics. Meat Science, v.72, n.4, p.741-750, 2006.

Hamm, R. Biochemistry of meat hydratation. Advances in Food Research Cleveland, v.10, n.2, p. 435-443, 1960.

MALHEIROS, Jessica Moraes. Identificação e quantificação das proteínas miofibrilares, isoformas da cadeia pesada de miosina (MyHC) e o amaciamento da carne de bovinos Nelore (Bos indicus). 2014. xvi, 64 p. Dissertação (mestrado) - Universidade Estadual Paulista Júlio de Mesquita Filho, Faculdade de Ciências Agrárias e Veterinárias, 2014.

Osório, J. C., Osório, M. T., Jardim, P. O., et al. Métodos para avaliação da produção da carne ovina: in vivo, na carcaça e na carne. Pelotas: Editora Universitária, 1998. 107 p.

SCHIRMER, B.C. et al. Characterization of the bacterial spoilage flora in marinated pork products. Journal of Applied Microbiology, v.106, n.6, p.2106-2116, 2009.

SCHLINDWEIN, M.M.; KASSOUF, A.L. Análise da influência de alguns fatores socioeconômicos e demográficos no consumo domiciliar de carnes no Brasil. Revista de Economia e Sociologia Rural, v.44, n.3, p.549-572, 2006.

SEDGHI, Habib et al. Effect of sodium lactate /sodium diacetate in combination with sodium nitrite on physiochemical, microbial properties and sensory evaluation of cow sausage. Potravinarstvo, [s.1.], v. 8, n. 1, p.239-246, 25 nov. 2014.

SHEARD, P.R.; TALI, A. Injection of salt, tripolyphosphate and bicarbonate marinade solutions to improve the yield and tenderness of cooked pork loin. Meat Science, v.68, n.2, p.305-311, 2004.

SILVA, N. V. da et al. Características de carcaça e carne ovina: uma abordagem das variáveis metodológicas e fatores de influência. Acta Veterinária Brasilica, Mossoró, v. 2, n. 4, p.103-110, jan. 2008.

SILVA, Rafael Xavier Araújo et al. Lactato de sódio, nisina e sua combinação na validade comercial da linguiça Toscana embalada a vácuo e estocada a $4^{\circ} \mathrm{C}$. Ciência Rural, , v. 44, n. 4, p. 746-751, apr. 2014.

Vlahova-Vangelova D, Dragoev S, Balev D, Assenova B, Amirhanov K. Quality, microstructure, and technological properties of sheep meat marinated in three different ways. Journal of Food Quality; 2017.

XIONG, Y.L. Role of myofibrillar proteins in water-binding in brine-enhanced meats. Food Research International, v.38, n.3, p.281-287, 2005.

ZEOLA, Nivea M. B. L et al. Avaliação da injeção de cloreto de cálcio nos parâmetros qualitativos da carne de ovelha. R. Bras. Agrociência, Pelotas, v. 11, n. 3, p.361-364, jul. 2005. 